\title{
Assessment of the FINDRISC tool in predicting the risk of developing type 2 diabetes mellitus in a young adult Nigerian population
}

\author{
Anthony Chibuzor Nnamudi ${ }^{*} \mathbb{C}$, Noghayin E. Jerry Orhue ${ }^{2}$ and Ifeoma Irene ljeh ${ }^{1}$
}

\begin{abstract}
Background: The global prevalence of diabetes mellitus is assuming worrisome proportions even among children and young adults. This study is aimed at predicting the risk of developing type 2 diabetes mellitus in a young adult Nigerian population using the validated FINDRISC tool.

Results: Data on 134 young adults [67 (50.0\%) male and 67 (50.0\%) female] analyzed in this study revealed a body mass index value of $24.86 \pm 3.38 \mathrm{~kg} / \mathrm{m}^{2}$ (male) and $25.42 \pm 5.39 \mathrm{~kg} / \mathrm{m}^{2}$ (female) with $43.2 \%$ of participants being overweight or obese. A waist circumference of $85.94 \pm 9.69 \mathrm{~cm}$ (male) and $83.92 \pm 15.24 \mathrm{~cm}$ (female) was recorded with $35.8 \%$ of participants having central obesity. A fasting blood glucose level of $82.04 \pm 14.52 \mathrm{mg} / \mathrm{dL}$ (male) and $84.89 \pm 18.30 \mathrm{mg} / \mathrm{dL}$ (female) was recorded with $32.8 \%$ of participants being hyperglycemic. The Finnish Diabetes Risk Scoring (FINDRISC) data [4.86 \pm 3.24 (male) and $7.31 \pm 3.38$ (female)] showed that 1.5\% have a high risk (FINDRISC $15-20$ ) while $12.0 \%$ have a moderate to high risk (FINDRISC $\geq 12$ ) of developing diabetes.

Conclusion: The FINDRISC tool is an effective diagnostic tool for assessing diabetes risk. In future studies, there may be need to also develop a more specific indigenous risk assessment tool particularly for a young adult Nigerian population.
\end{abstract}

Keywords: BMI, Fasting blood glucose, Diabetes mellitus, FINDRISC, Nigeria, Young adults

\section{Background}

Diabetes mellitus refers to a group of metabolic disorders characterized by a state of chronic hyperglycemia due to defects in insulin secretion, insulin action or both (Ozougwu et al. 2013). Diabetes is a non-communicable disease of the endocrine system resulting from multiple etiologies in secretion of insulin by the islet cells of Langerhans (Todkar 2016; Omondanisi et al. 2017).

Type 1 diabetes (previously known as insulindependent, juvenile or childhood-onset diabetes) has

\footnotetext{
*Correspondence: annamudi@pums.edu.ng; anthonynnamudi@gmail.com ${ }^{1}$ Department of Biochemistry, Faculty of Basic Medical Sciences, PAMO University of Medical Sciences, Port Harcourt, Nigeria

Full list of author information is available at the end of the article
}

been described as an organ-specific autoimmune disease that leads to the complete loss of the insulinproducing $\beta$-cells in the pancreatic islets by autoreactive T-lymphocytes leading to insulin deficiency and a consequent elevated level of plasma glucose (Yu 2012; Ali 2013). Gestational diabetes, diagnosed through prenatal screening, occurs in pregnancy with long-term risk of type 2 diabetes (World Health Organization 2016). Type 2 diabetes (previously known as non-insulin-dependent or adult-onset diabetes), being the most prevalent form, typically results when insulin secretion from the islets fails to keep pace with increasing insensitivity to the action of circulating insulin on its target tissues characterized by the elevated level of plasma glucose (Ali 2013). Although it was previously 
considered as a disease of the middle-aged and elderly, it has begun to occur in younger persons.

Elevated blood glucose level is a common manifestation of uncontrolled diabetes. This leads to serious damages to the heart, blood vessels, eyes, kidneys and nerves (World Health Organization 2016). Long-term macrovascular and microvascular complications such as nephropathy, neuropathy and retinopathy are commonly associated with diabetes and they pose imminent challenge to diabetes management.

A global estimate of 463 million people living with diabetes alongside 4.2 million diabetes-related deaths has been reported. The current global diabetes burden is projected to hit 700 million by 2045 (International Diabetes Federation 2019). An estimated 193 million people with undiagnosed diabetes in 2015 increased to 232 million in 2019. As such, they are predisposed to a greater risk of developing complications (International Diabetes Federation 2019, 2015). Nigeria leads subSaharan Africa with the highest burden of diabetes with an estimated 3.9 million cases, equivalent to an extrapolated prevalence of $4.99 \%$ of the adult population aged between 20 and 79 years. An annual increase of 125,000 diabetes-related deaths has been estimated between 2010 and 2030 (Dahiru et al. 2016). It suffices to state that global healthcare expenditure on diabetes continues to be on the rise, thus making diabetes a major global health concern, especially in the developing and underdeveloped nations of the world. This is easily linked to the fact that healthcare budgeting is often times, not prioritized in these nations. A large number of diabetes cases occur in these low-income nations.

Whereas the efforts to prevent the disease should be targeted at individuals who are at high risk for the disease, (Lindström and Tuomilehto 2003) identification of these individuals is a major focus of various diabetes risk scoring models. Diabetes risk scoring models are cost-effective diagnostic tools for assessing an individual's risk of developing type 2 diabetes mellitus over a defined period of time.

The Finnish Diabetes Risk Score (FINDRISC), developed by Lindström and Tuomilehto for the Finnish Diabetes Association, is a simple, cheap, noninvasive, reliable and fast tool that has been validated for identifying individuals at high risk for type 2 diabetes mellitus based on 10-year prospective data from a population-based cohort (Lindström and Tuomilehto 2003). FINDRISC has been validated in type 2 diabetes risk prediction in European populations (Janghorbani et al. 2013; Makrilakis et al. 2011; Wang et al. 2010), a Jordanian young student population (Al-Shudifat et al. 2017) and adult Nigerian populations (Agu et al. 2015; Alebiosu et al. 2012).

\section{Methods}

The aim of this study is to predict the risk of developing type 2 diabetes mellitus in a young adult population in Nigeria using the validated FINDRISC tool. This is necessary as the identification of individuals at risk will enable such individuals to begin to adopt a series of necessary lifestyle changes within the shortest time frame.

In predicting type 2 diabetes, the validated FINDRISC tool scores eight components: age, body mass index (BMI), waist circumference, physical activity, consumption of vegetables, fruits and berries, use of antihypertensives, previous diagnosis of high blood glucose and family history of diabetes.

\section{Participants}

A population-based cohort study was carried out to assess the risk of developing type 2 diabetes mellitus among young adults (aged 15-35 years) in Asaba, Delta State, Nigeria, using the validated Finnish Diabetes Risk Score (FINDRISC) tool.

\section{Informed consent and Ethics Committee approval}

An informed consent form designed in accordance with the guidelines of the research ethics review committee of World Health Organization was distributed to the participants. Only participants who filled the informed consent form thereby indicating their willingness to freely participate in the study took part in the study. Ethical clearance was obtained from the Delta State Ministry of Health Research Ethics Committee, Asaba, Nigeria (HM/596/T/55). Male and female participants were selected by convenience sampling without any form of prejudice. Participants were not coerced into participation, and they were duly informed that they reserved the right to opt out of the study without facing any consequences of any kind.

\section{Exclusion criteria}

The conditions for exclusion of a participant from the study are as follows: a prior diagnosis of diabetes, a fasting blood glucose of $\geq 126 \mathrm{mg} / \mathrm{dL}$, use of prescribed drugs or diets for diabetes control and management as well as a decline of consent.

\section{Sample size}

The sample size was determined using the Vaughan's formula (Vaughan and Morrow 1989) as reported by Agu et al. (2015)

$$
N=\frac{P Q}{(E / 1.96)^{2}}
$$

$N$ is sample size; $P$ is maximum expected prevalence rate of diabetes mellitus; $Q$ is $100-P$; $E$ is margin of sample 
error tolerated in percentage $(5 \%$ being the maximum accepted value).

Considering a $4.5 \%$ error margin and a diabetes prevalence rate of 5.4\% in Delta State, Nigeria, (Oguoma et al. 2015; Adeloye et al. 2017) a minimum sample size of 97 participants was recommended for the study. However, in order to make adequate provisions for errors in filling of questionnaires due to inconsistency and possible data losses, a total sample size of 140 was adopted.

\section{Blood glucose measurement}

The fasting blood sugar of participants was determined by thumb-pricking using a sterilized lancet. A drop of blood was tested on the glucose test strip using a standard glucometer (Accu-Chek Active, Roche Mannheim, Germany).

\section{The FINDRISC tool}

The FINDRISC tool, designed by Lindström and Tuomilehto in 2003, is a widely used tool for predicting the risk of developing diabetes mellitus. In this tool, eight variable components that are linked with anthropometric and lifestyle patterns are scored. These components include age, BMI, waist circumference, physical activity, consumption of vegetables, fruits or berries, blood pressure medication, previous diagnosis of high blood sugar and family history of diabetes.

(a) Anthropometric measurements The participants' weight was measured in kilograms, to the nearest $0.1 \mathrm{Kg}$ using a standard weighing scale (Hana model, China) while ensuring that the participant was wearing light clothing and he or she wore no shoes. A stadiometer was used to measure participants' height to the nearest $0.1 \mathrm{~cm}$. Participants' body mass index (BMI) was calculated using the formula:

$$
\mathrm{BMI}=\frac{\text { Weight }(\mathrm{kg})}{\text { Height }^{2}\left(\mathrm{~m}^{2}\right)}
$$

Waist circumference was measured with the participant in an erect posture. Similarly, participants' hip circumference was measured. This was used to calculate the participant's waist-to-hip ratio.

(b) Risk score calculation The variable components of the validated FINDRISC tool were scored to determine a participants' diabetes risk score. The age component was scored as follows: under 45 years scored 0 point; 45-54 years scored 2 points; 55-64 years scored 3 points; and over 64 years scored 4 points. The BMI component was scored as follows: $<25 \mathrm{~kg} / \mathrm{m}^{2}$ scored 0 point; $25-30 \mathrm{~kg} / \mathrm{m}^{2}$ scored 1 point; $>30 \mathrm{~kg} / \mathrm{m}^{2}$ scored 3 points. The waist circumference component was scored as follows: $<94 \mathrm{~cm}$ for men or $<80 \mathrm{~cm}$ scored 0 point;
94-102 $\mathrm{cm}$ for men or $80-88 \mathrm{~cm}$ for women scored 3 points; and $>102 \mathrm{~cm}$ for men or $>88 \mathrm{~cm}$ for women scored 4 points. The physical activity component was scored as follows: a physical activity of at least $30 \mathrm{~min}$ on a daily basis scored 0 point; if less, it scored 2 points. The consumption of vegetables, fruits or berries component was scored as follows: a daily consumption of vegetables, fruits or berries scored 0 point; if not every day, it scored 1 point. The use of antihypertensive component was scored as follows: a regular use of antihypertensive was scored 2 points; if not, it scored 0 point. The previous diagnosis of high blood glucose component was scored as follows: a previous diagnosis of high blood glucose in the past (either in a health examination, illness or pregnancy) scored 5 points; if not, it scored 0 point. The family history of diabetes component was scored as follows: a parent, brother, sister or own child having been diagnosed of diabetes scored 5 points; a grandparent, aunt, uncle or first cousin having been diagnosed of diabetes scored 3 points; if none of these immediate family or relatives have been diagnosed, it scored 0 point.

At the end of the risk scoring process, every participant was informed of his/her score and appropriate health education was offered as part of benefits of participation in this study. In particular, high scoring participants were strongly advised on the need for regular blood sugar testing. The participants' total risk score was summed up from the respective scores of the different components followed by analysis and comparison. The total risk score was classified as follows: $<7$ (low risk-an estimated 1 in 100 will develop disease); $7-11$ (slightly elevated risk-an estimated 1 in 25 will develop disease); 12-14 (moderate risk-an estimated 1 in 6 will develop disease); $15-20$ (high risk-an estimated 1 in 3 will develop disease); $>20$ (very high risk-an estimated 1 in 2 will develop disease).

\section{Statistical analysis}

Data were analyzed on the basis of sex and age group and where appropriate, data were reported as mean \pm standard deviations. The prevalence of the risk profile was determined as a ratio of the number of participants presenting with the particular risk category and the total number of participants multiplied by 100 . Descriptive data analysis was done using Statistical Package for the Social Sciences (SPSS) version 23.0 (SPSS Inc Chicago IL), while charts were generated with Microsoft Excel 2003 (Microsoft Corporation US).

\section{Results}

In this study, a total of 140 participants were surveyed while 6 participants were excluded, having satisfied one or more of the exclusion criteria. Thus, the final analysis included 134 participants representing a response 
rate of $95.71 \%$. The socio-demographic characteristics and mean data of the participants are presented in Table 1. Among the 134 young adults, 67 (50.0\%) were male and 67 (50.0\%) were female. The participants' age ranged from 15 to 35 years with the modal age range being $26-30$ years.

The female participants had higher mean values of BMI (25.42 \pm 5.39 vs $24.86 \pm 3.38)$, fasting blood sugar $(84.89 \pm 18.30$ vs $82.04 \pm 14.52)$ and FINDRISC score $(7.31 \pm 3.38$ vs $4.86 \pm 3.24)$ relative to the males. On the other hand, the male participants had higher mean values of waist circumference $(85.94 \pm 9.69$ vs $83.92 \pm 15.24)$ and hip circumference $(97.79 \pm 9.77$ vs $96.28 \pm 14.99)$ relative to the females. The mean values of waist-to-hip ratio for males $(0.87 \pm 0.05)$ compare with those of the females $(0.87 \pm 0.06)$.
The distribution of participants' waist circumference (Table 2) shows that $60(44.8 \%)$ males and $26(19.4 \%)$ females had waist circumference less than $94 \mathrm{~cm}$ (for male) and less than $80 \mathrm{~cm}$ (for female). 1 (0.7\%) male and 18 (13.4\%) females had waist circumference ranging from 94 to $102 \mathrm{~cm}$ (for male) and 80 to $88 \mathrm{~cm}$ (for female). Also, 6 (4.5\%) males and 23 (17.2\%) females had waist circumference greater than $102 \mathrm{~cm}$ (for male) and greater than $88 \mathrm{~cm}$ (for female). Summarily, 48 (35.8\%) of the participants had waist circumference above the threshold value of less than $94 \mathrm{~cm}$ for male and less than $80 \mathrm{~cm}$ for female. The distribution of participants' waist-to-hip ratio (Table 2) shows that $44(32.8 \%)$ males and 7 (5.2\%) females had waist-to-hip ratio less than 0.9 (for male) and less than 0.8 (for female). 23 (17.2\%) males and 60 (44.8\%) females had waist-to-hip ratio greater than 0.9 (for male) and greater than 0.8 (for female). Summarily, 83 (62.0\%)

Table 1 Socio-demographic characteristics and mean data of participants

\begin{tabular}{|c|c|}
\hline Sex & Frequency (\%) \\
\hline Male & $67(50.0 \%)$ \\
\hline Female & $67(50.0 \%)$ \\
\hline Total & $134(100.0 \%)$ \\
\hline Age (years) & Frequency (\%) \\
\hline $15-20$ & $25(18.7 \%)$ \\
\hline $21-25$ & $35(26.1 \%)$ \\
\hline $26-30$ & $39(29.1 \%)$ \\
\hline $31-35$ & $35(26.1 \%)$ \\
\hline Total & $134(100.0 \%)$ \\
\hline BMI & Mean $\pm S D\left(k g / \mathrm{m}^{2}\right)$ \\
\hline Male & $24.86 \pm 3.38$ \\
\hline Female & $25.42 \pm 5.39$ \\
\hline Waist circumference & Mean $\pm S D(\mathrm{~cm})$ \\
\hline Male & $85.94 \pm 9.69$ \\
\hline Female & $83.92 \pm 15.24$ \\
\hline Hip circumference & Mean \pm SD $(\mathrm{cm})$ \\
\hline Male & $97.79 \pm 9.77$ \\
\hline Female & $96.28 \pm 14.99$ \\
\hline Waist-to-hip ratio & Mean \pm SD \\
\hline Male & $0.87 \pm 0.05$ \\
\hline Female & $0.87 \pm 0.06$ \\
\hline Fasting blood sugar & Mean $\pm \mathrm{SD}(\mathrm{mg} / \mathrm{dL})$ \\
\hline Male & $82.04 \pm 14.52$ \\
\hline Female & $84.89 \pm 18.30$ \\
\hline FINDRISC score & Mean \pm SD \\
\hline Male & $4.86 \pm 3.24$ \\
\hline Female & $7.31 \pm 3.38$ \\
\hline
\end{tabular}


Table 2 Distribution of waist circumference and waist-to-hip ratio

\begin{tabular}{llll}
\hline Male $(\mathrm{m})$, female $(\mathbf{f})$ & Male frequency (\%) & Female frequency (\%) & Total frequency (\%) \\
\hline $\begin{array}{lll}\text { Waist circumference }(\mathrm{cm}) \\
<94(\mathrm{~m}),<80(\mathrm{f})\end{array}$ & $60(44.8 \%)$ & $26(19.4 \%)$ & $86(64.2 \%)$ \\
$94-102(\mathrm{~m}), 80-88(\mathrm{f})$ & $1(0.7 \%)$ & $18(13.4 \%)$ & $19(14.1 \%)$ \\
$>102(\mathrm{~m}),>88(\mathrm{f})$ & $6(4.5 \%)$ & $23(17.2 \%)$ & $29(21.7 \%)$ \\
Total & $67(50.0 \%)$ & $67(50.0 \%)$ & $134(100.0 \%)$ \\
Waist-to-hip ratio & & & $51(38.0 \%)$ \\
$<0.9(\mathrm{~m}),<0.8(\mathrm{f})$ & $44(32.8 \%)$ & $7(5.2 \%)$ & $83(62.0 \%)$ \\
$>0.9(\mathrm{~m}),>0.8(\mathrm{f})$ & $23(17.2 \%)$ & $60(44.8 \%)$ & $134(100 \%)$ \\
Total & $67(50.0 \%)$ & $67(50.0 \%)$ & \\
\hline
\end{tabular}

Table 3 Distribution of FINDRISC, BMI and fasting blood sugar level across gender

\begin{tabular}{|c|c|c|c|}
\hline & Risk & Male (\%) & Female (\%) \\
\hline \multicolumn{4}{|c|}{ FINDRISC score } \\
\hline$<7$ & Low & $47(70.1 \%)$ & 38 (56.7\%) \\
\hline $7-11$ & Slightly elevated & $13(19.4 \%)$ & 20 (29.9\%) \\
\hline $12-14$ & Moderate & $5(7.5 \%)$ & $9(13.4 \%)$ \\
\hline $15-20$ & High & $2(3.0 \%)$ & $0(0.0 \%)$ \\
\hline \multicolumn{4}{|c|}{$\mathrm{BMI}\left(\mathrm{kg} / \mathrm{m}^{2}\right)$} \\
\hline$<25$ & Healthy weight & $41(61.2 \%)$ & 35 (52.2\%) \\
\hline $25-29.9$ & Overweight & $21(31.3 \%)$ & $21(31.3 \%)$ \\
\hline$\geq 30$ & Obesity & $5(7.5 \%)$ & 11 (16.4\%) \\
\hline \multicolumn{4}{|c|}{$\mathrm{FBS}(\mathrm{mg} / \mathrm{dl})$} \\
\hline$<54$ & Hypoglycemic & $3(4.5 \%)$ & $5(7.5 \%)$ \\
\hline $54-90$ & Normoglycemic & $45(67.2 \%)$ & 37 (55.2\%) \\
\hline $91-125$ & Hyperglycemic & $19(28.3 \%)$ & $25(37.3 \%)$ \\
\hline
\end{tabular}

of the participants had waist-to-hip ratios higher than the threshold value of less than 0.9 (for male) and 0.8 (for female).

In Table 3, the FINDRISC score distribution shows that a large proportion of the participants represented as $47(70.1 \%)$ males and $38(56.7 \%)$ females have a low risk (FINDRISC $<7$ ) while $7(10.5 \%)$ males and $9(13.4 \%)$ females have a moderate to high risk (FINDRISC $\geq 12$ ) of developing diabetes mellitus. The BMI distribution shows that 41 (61.2\%) males and 35 (52.2\%) females had a healthy weight while $26(38.8 \%)$ males and $32(47.7 \%)$ females were either overweight or obese. Also, 45 (67.2\%) males and 37 (55.2\%) females were normoglycemic while 19 (28.3\%) male and 25 (37.3\%) females were hyperglycemic.

The distribution of FINDRISC score, BMI and fasting blood glucose across the various age groups is presented in Table 4. The FINDRISC score distribution shows that 1 (4.0\%) of the participants aged 15-20 years and 1 (2.9\%) of the participants aged 31-35 years had high risk scores.
The BMI distribution shows that $21(84.0 \%)$ of the participants aged 15-20 years had a healthy weight, 14 (40.0\%) of the participants aged 21-25 years were overweight, while $8(22.9 \%)$ of the participants aged $31-35$ years were obese. Also, 15 (38.5\%) of the participants aged 26-30 years had hyperglycemia representing the highest prevalence of hyperglycemia per age group.

From Fig. 1, 85 (63.4\%) participants had a FINDRISC score less than 7, indicating a low risk, 33 (24.6\%) participants had a FINDRISC score 7-11, indicating a slightly elevated risk, 14 (10.5\%) participants had a FINDRISC score $12-14$, indicating a moderately elevated risk while 2 (1.5\%) participants had a FINDRISC score 15-20, indicating a high risk. Taken together, $12.0 \%$ of participants have a moderately elevated to high risk (FINDRISC $\geq 12$ ) of developing diabetes in the next 10 years.

Figure 2 shows that 76 (56.7\%) participants had a BMI less than 25 , indicating a healthy weight, 42 (31.3\%) participants had a BMI 25-29.9 indicating overweight and $16(11.9 \%)$ participants had a BMI greater than 30, indicating obesity. Taken together, 58 (43.2\%) participants were either overweight or obese $(\mathrm{BMI} \geq 25)$.

Figure 3 shows that $8(6.0 \%)$ participants were hypoglycemic. Eighty-two (61.2\%) participants were normoglycemic. Forty-four (32.8\%) participants were hyperglycemic.

\section{Discussion}

Diabetes mellitus is a disease characterized by high prevalence which often goes undiagnosed until advanced complications have already set in (World Health Organization 2016; Saleem et al. 2017). In the face of increasing prevalence of diabetes, poor healthcare systems, high cost of diabetes management and a tendency towards lifelong management, concerted efforts aimed at preventing the onset or progression of the disease must be sustained. This study was therefore carried out to predict the risk of developing type 2 diabetes mellitus in a young adult Nigerian population 


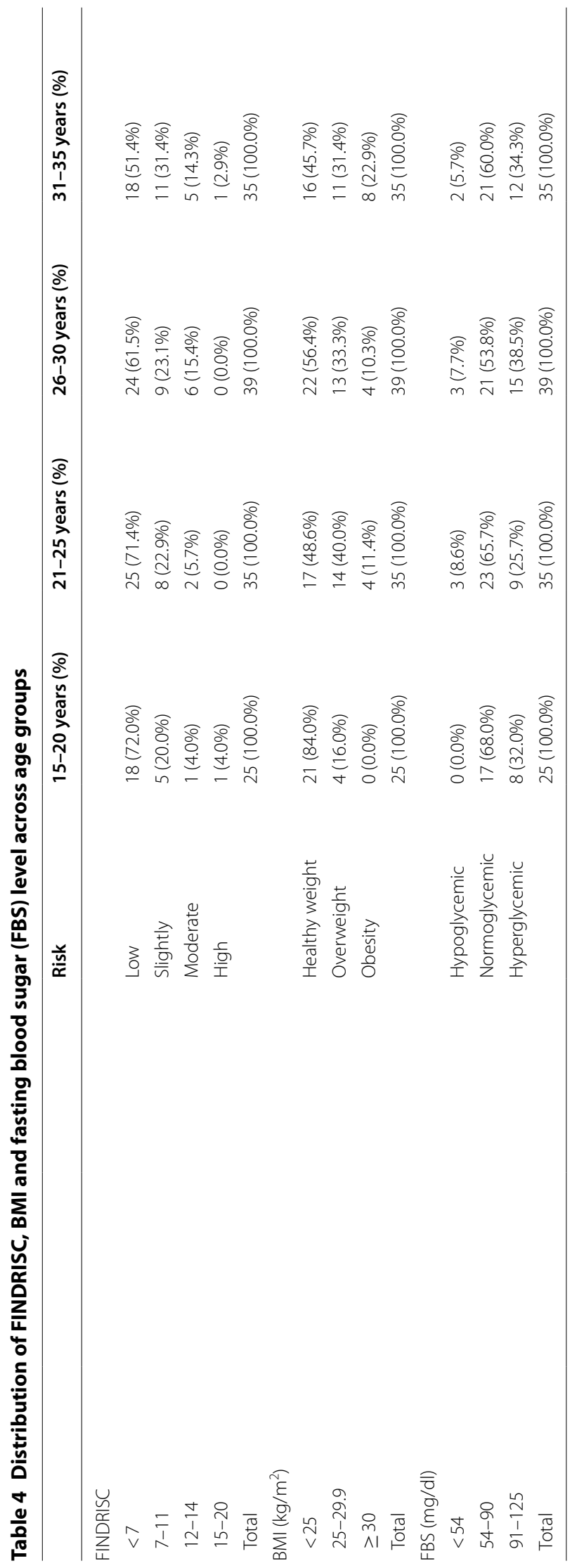




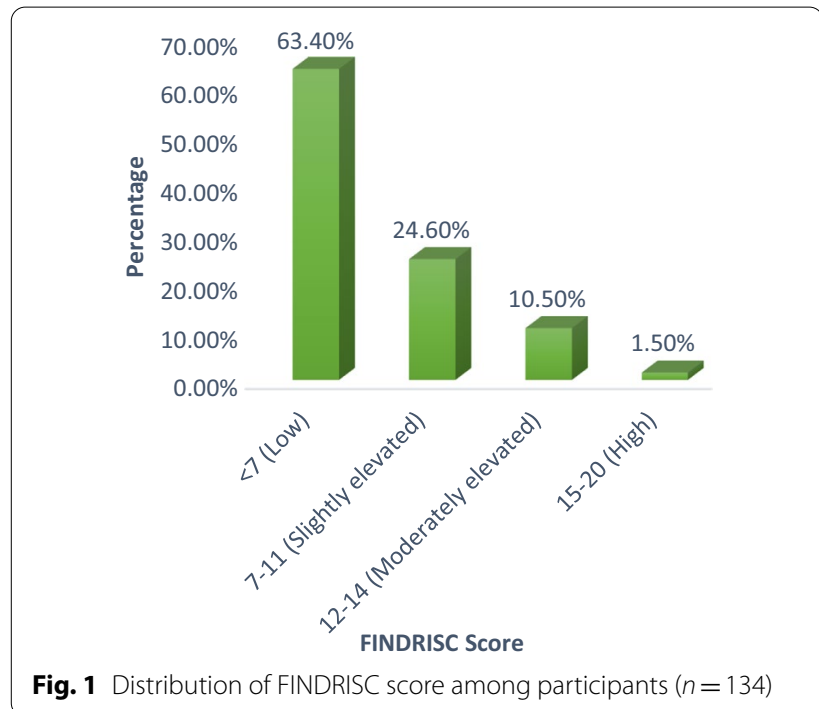

Fig. 1 Distribution of FINDRISC score among participants $(n=134)$

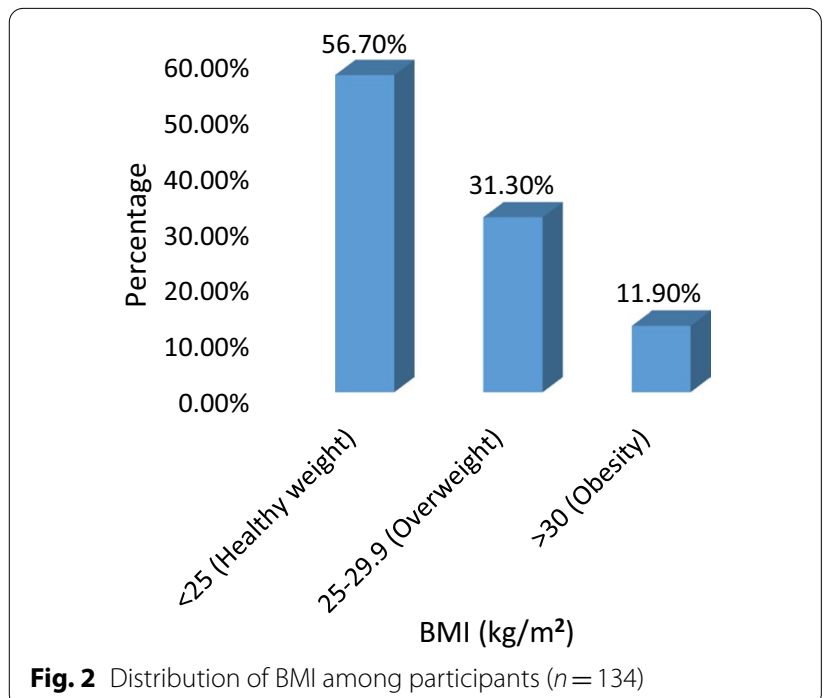

using the FINDRISC tool. This tool has been recognized as an effective tool for screening individuals at high risk for type 2 diabetes mellitus as well as identifying undetected type 2 diabetes mellitus, abnormal glucose tolerance and metabolic syndrome (Al-Shudifat et al. 2017).

In this present study, a $10.50 \%$ moderate risk and $1.50 \%$ high risk of developing type 2 diabetes mellitus is reported in a young adult Nigerian population. This result is comparable to a $5.2 \%$ moderate risk and $1.8 \%$ high risk reported in a study conducted among young students in Jordan (Al-Shudifat et al. 2017). Earlier findings in a Nigerian population had reported a $9.1 \%$ high risk (Alebiosu et al. 2012) and a 9.0\% high risk (Agu et al. 2015) of developing diabetes mellitus. Both

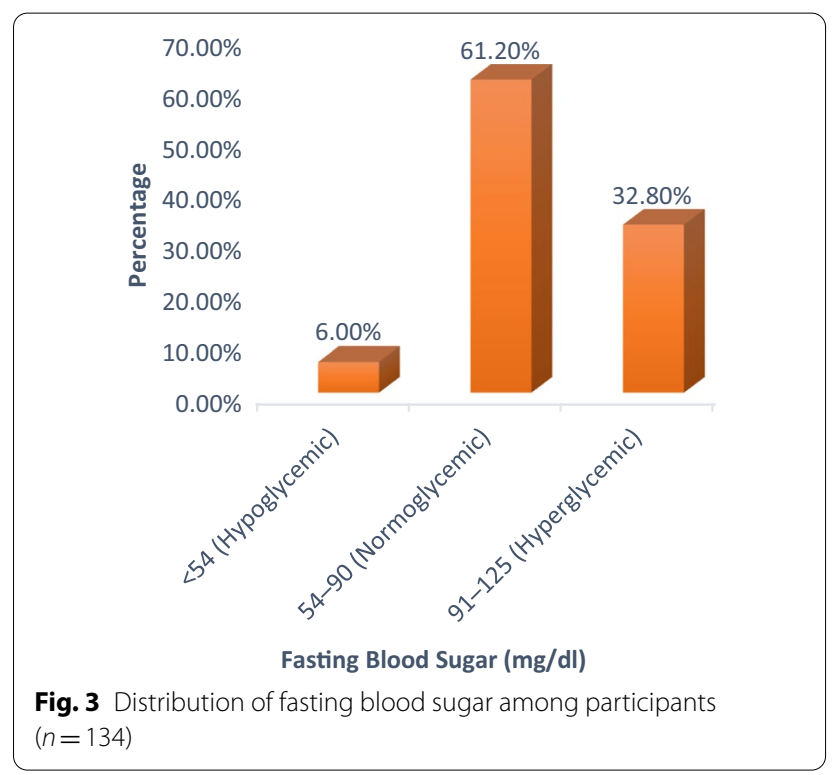

studies were carried out among elderly and aged adult Nigerians. Furthermore, in identifying individuals at high risk, there is a conventional practice of adopting different FINDRISC cutoff values by different authors. A FINDRISC cutoff value of 12 had been previously adopted. These studies reported that 13\%, (Saaristo et al. 2005) 22.61\%, (Saleem et al. 2017) and 29\% (Agu et al. 2015) of study participants had a FINDRISC score above the cutoff value of 12 . This is comparable to the findings of this present study which reported that $12.0 \%$ of participants have a moderately elevated to high risk of developing diabetes in the next 10 years. This is a population-based study conducted without gender bias in sampling, suggesting that young adults may be at increasing risk of developing type 2 diabetes mellitus due to prevalent modifiable risk factors. This underscores the need for urgent steps to be taken to stem the tide.

Waist circumference is one of the components of the Adult Treatment Panel III (ATP III) and the International Diabetes Federation (IDF) definitions of metabolic syndrome. It is appropriate to have different cutoff values for waist circumference across gender (Stevens et al. 2010). A waist circumference greater than $102 \mathrm{~cm}$ (for males) and greater than $88 \mathrm{~cm}$ (for females) is indicative of a higher risk of diabetes and cardiovascular diseases (Agu et al. 2015). This study reported a slightly higher waist circumference in males $(85.94 \pm 9.69 \mathrm{~cm})$ relative to females $(83.92 \pm 15.24 \mathrm{~cm})$. However, there were more females (17.2\%) than males (4.5\%) that reached the threshold values (>102 cm in males, $>88 \mathrm{~cm}$ in females). This is a common pattern in Nigerian populations (Agu et al. 2015; 
Alebiosu et al. 2012). Also, even though similar waist-tohip ratio values were reported in this study across gender $(0.87 \pm 0.05$ and $0.87 \pm 0.06$ for male and female participants, respectively), more females (44.8\%) compared to males $(17.2 \%)$ attained the threshold values of $(>0.9$ for males, $>0.8$ for females). Measures of central adiposity (including a higher waist circumference and particularly, a higher waist-to-hip ratio) are more strongly associated with a greater risk of myocardial infarction in women than in men (Peters et al. 2018). The implication is that that these young females may be at greater risk of heart attack.

Overweight and obesity are associated with non-communicable diseases like diabetes (Puepet et al. 2002). This study reported a slightly higher BMI in females $(25.42 \pm 5.39 \mathrm{~cm})$ relative to males $(24.86 \pm 3.38 \mathrm{~cm})$ as well as a higher prevalence of overweight and obesity in female participants $(47.7 \%)$ than males $(38.8 \%)$. This is similar to the pattern reported in an earlier study among young adult Nigerians (Ejike and Ijeh 2012) and other previous reports that have suggested low levels of physical activity in females as well as genetic and hormonal differences as possible reasons for this observed pattern (Okafor et al. 2014; Pouane et al. 2012). Also, 31.3\% of participants were overweight (BMI 25-29.9) while 11.9\% of participants were obese (BMI $\geq 30$ ). This is consistent with earlier reports of an overweight prevalence range of $17.2-35.1 \%$ and an obesity prevalence range of $4.2-22.2 \%$ in previously studied Nigerian populations (Puepet et al. 2002; Okafor et al. 2014; Chukwuonye et al. 2013). However, the finding of this study is striking, considering the fact that earlier reports studied elderly and aged adult Nigerian populations whereas this study was conducted in a young adult population. Given that this study was conducted in an urban area, the prevalence of overweight and obesity may be associated with a sedentary lifestyle among these young adults. A high prevalence of sedentary lifestyle and obesity among urban dwellers has been reported (Agu et al. 2015; Adaramaja et al. 2010; Christensen et al. 2009).

This study reported a slightly higher fasting blood glucose level in females $(84.89 \pm 18.30 \mathrm{mg} / \mathrm{dL})$ relative to males $(82.04 \pm 14.52 \mathrm{mg} / \mathrm{dL})$ as well as a higher prevalence of hyperglycemia in female participants (37.3\%) than males $(28.3 \%)$. Also, $32.80 \%$ of participants had impaired fasting glucose $(90-125 \mathrm{mg} / \mathrm{dL})$. Previous studies in Nigerian populations had reported a prediabetes prevalence of $6 \%$ and $1.1 \%$ which are at variance with the findings of this study. This discrepancy may be partly due to the cutoff values of $6.1-6.9 \mathrm{mmol} / \mathrm{L}$ or $110-125 \mathrm{mg} /$ $\mathrm{dL}$ adopted by these studies conducted among elderly and aged adult Nigerian populations (Shittu et al. 2017; Ejike et al. 2015). Considering the peculiarity of this present study population, a hyperglycemic cutoff value of 90-125 mg/dL was defined. Prediabetes, a state of intermediate hyperglycemia in which blood glucose levels are above normal but below the defined threshold of diabetes is an at-risk state for development of diabetes with yearly conversion rate of $5-10 \%$ (Bansal 2015). The result of this study therefore suggests a possibility of an impending surge in cases of diabetes in Asaba.

\section{Limitations and strengths}

This study is limited by the mode of data collection. As usual with most studies on diabetes risk scoring, the data are subjective and objective. There is the tendency for the participant to under-report negative characteristics and even amplify positive characteristics. A similar weakness has been previously reported (Al-Shudifat et al. 2017). However, the incorporation of blood sugar testing in the study design is advantageous. Furthermore, this study was carried out in an urban setting in Nigeria. There is therefore need to do a follow-up study in a rural Nigerian setting for the purpose of comparison and generalizability to other Nigerian populations.

A major strength of this study is the sampling of young adults who are apparently healthy without any suspected chronic health complications common to elderly and aged adult populations. A similar strength has been previously reported (Ejike and Ijeh 2012).

\section{Conclusion}

The fasting blood sugar test conducted vis-à-vis the risk scoring provide sufficient evidence for a high prevalence of prediabetes and an impending surge in cases of diabetes among participants in the study population. The onset of metabolic syndrome is also a highly probable outcome considering the anthropometric data obtained from this study. The FINDRISC tool is an effective diagnostic tool for assessing diabetes risk within a 10-year prospective period. In future studies, there may be need to also develop a more specific indigenous risk assessment tool particularly for a young adult Nigerian population.

\section{Abbreviations \\ FINDRISC: Finnish Diabetes Risk Score; BMI: Body mass index.}

\section{Acknowledgements \\ The Federal Government of Nigeria is hereby acknowledged for the award of a Federal Government postgraduate scholarship to Anthony C. Nnamudi. The authors are grateful to all the young adults who participated in the study. The authors are equally grateful to Vincent Onyeche, Ifeoma Onyeche and Elizabeth Ibegbulem for their invaluable assistance.}

\section{Authors' contributions}

ACN was responsible for acquisition, analysis and interpretation of data. NEJO and III contributed to the conception and design of the study. ACN drafted the article. ACN, NEJO and III did critical revision of the article. All authors read and approved the final manuscript. 


\section{Funding}

This research was supported by a Federal Government of Nigeria postgraduate scholarship (FSBA/FGSS/18/PG/015) awarded to Anthony Chibuzor Nnamudi. However, the study sponsor was not involved in the design of the study; the collection, analysis and interpretation of data; writing the report; or the decision to submit the report for publication.

\section{Availability of data and materials}

The datasets used and analyzed during the current study are available from the corresponding author on reasonable request.

\section{Ethics approval and consent to participate}

Ethical clearance was obtained from the Delta State Ministry of Health Research Ethics Committee, Asaba, Nigeria (HM/596/T/55). Only participants who read, understood and signed the informed consent form were allowed to take part in the study.

\section{Consent for publication}

Not applicable.

\section{Competing interests}

The authors declare that they have no competing interests.

\section{Author details}

${ }^{1}$ Department of Biochemistry, Faculty of Basic Medical Sciences, PAMO University of Medical Sciences, Port Harcourt, Nigeria. ${ }^{2}$ Department of Biochemistry, Faculty of Life Sciences, University of Benin, Benin City, Nigeria.

Received: 14 January 2020 Accepted: 22 October 2020

Published online: 03 November 2020

\section{References}

Adaramaja SR, Abdullahi AA, Adekeye DS (2010) Sedentary life style and wellness in Kaduna State, Nigeria. Ethno Med 4:15-19

Adeloye D, Ige JO, Aderemi AV et al (2017) Estimating the prevalence, hospitalization and mortality from type 2 diabetes mellitus in Nigeria: a systematic review and meta-analysis. BMJ Open 7:e015424

Agu U, Agu MC, Nnaji GA (2015) Assessment of risk of developing diabetes mellitus among local government employees in Onitsha, south-eastern Nigeria. Epidemiol Rep 3:4

Al-Shudifat A-E, Al-Shdaifat A, Al-Abdouh AA et al (2017) Diabetes risk score in a young student population in Jordan: a cross-sectional study. J Diabetes Res 2017:8290710

Alebiosu CO, Ogunsemi OO, Abe OS et al (2012) The risk of developing type 2 Diabetes over 10 years in communities across Ogun State, Nigeria. J Clin Hypertens 14(1):119

Ali O (2013) Genetics of type 2 diabetes. World J Diabetes 4(4):114-123

Bansal N (2015) Prediabetes diagnosis and treatment: a review. World J Diabetes 6(2):296-303

Christensen DL, Friis H, Mwaniki DL et al (2009) Prevalence of glucose intolerance and associated risk factors in rural and urban populations of different ethnic groups in Kenya. Diabetes Res Clin Pract 84:303-310

Chukwuonye II, Chuku A, John C et al (2013) Prevalence of overweight and obesity in adult Nigerians - a systematic review. Diabetes Metab Syndr Obes 6:43-47

Dahiru T, Aliyu AA, Shehu AU (2016) A review of population-based studies on diabetes mellitus in Nigeria. Sub-Saharan Afr J Med 3:59-64

Ejike CECC, ljeh II (2012) Obesity in young-adult Nigerians: variations in prevalence determined by anthropometry and bioelectrical impedance analysis, and the development of \% body fat prediction equations. Int Arch Med 5:22

Ejike CECC, Uka NK, Nwachukwu SO (2015) Diabetes and pre-diabetes in adult Nigerians: Prevalence, and correlations of blood glucose concentrations with measures of obesity. Afr J Biochem Res 9(3):55-60
International Diabetes Federation (2019) Diabetes atlas, 9th edn. International Diabetes Federation, Brussels

International Diabetes Federation (2015) Diabetes atlas, 7th edn. International Diabetes Federation, Brussels

Janghorbani M, Adineh H, Amini M (2013) Evaluation of the Finnish Diabetes Risk Score (FINDRISC) as a screening tool for the metabolic syndrome. Rev Diabet Stud 10(4):283-292

Lindström J, Tuomilehto J (2003) The diabetes risk score: a practical tool to predict type 2 diabetes risk. Diabetes Care 26(3):725-731

Makrilakis K, Liatis S, Grammatikou S et al (2011) Validation of the Finnish diabetes risk score (FINDRISC) questionnaire for screening for undiagnosed type 2 diabetes, dysglycaemia and the metabolic syndrome in Greece. Diabetes Metab 37:144-151

Oguoma VM, Nwose EU, Skinner TC, Digban KA, Onyia IC, Richards RS (2015) Prevalence of cardiovascular disease risk factors among a Nigerian adult population: relationship with income level and accessibility to CVD risks screening. BMJ Public Health 15:397

Okafor Cl, Gezawa ID, Sabir AA, Raimi TH, Enang O (2014) Obesity, overweight, and underweight among urban Nigerians. Niger J Clin Pract 17(6):743-749

Omondanisi El, Aboua YG, Oguntibeju OO (2017) Assessment of the antihyperglycaemic, anti-inflammatory and antioxidant activities of the methanol extract of Moringa oleifera in diabetes-induced nephrotoxic male wistar rats. Molecules 22(4):E439

Ozougwu JC, Obimba KC, Belonwu CD, Unakalamba CB (2013) The pathogenesis and pathophysiology of type 1 and type 2 diabetes mellitus. J Physiol Pathophysiol 4(4):46-57

Peters SAE, Bots SH, Woodward M (2018) Measures of general and central adiposity and the risk of myocardial infarction: results from the UK biobank. J Am Heart Assoc 7:e008507

Pouane T, Steyn K, Bradshaw D et al (2012) Obesity in South Africa: the South African demographic and health survey. Obes Res 10:1038-1048

Puepet FH, Zoakah Al, Chuhwak EK (2002) Prevalence of overweight and obesity among urban Nigeria adults in Jos. Highl Med Res J 1(1):13-16

Saaristo T, Peltonen M, Saarikoski L, Sundvall J, Eriksson JG, Tuomilehto J (2005) Cross-sectional evaluation of the Finnish Diabetes Risk Score: a tool to identify undetected type 2 diabetes. Abnormal 2(2):67-72

Saleem SM, Khan SMS, Jan SS (2017) Finnish diabetic risk score: a tool for predicting risk of undiagnosed type 2 diabetes mellitus. Ann Med Health Sci Res 7:295-298

Shittu RO, Kasali FO, Biliaminu SA, Odeigah LO, Sule AG, Musah Y (2017) Prevalence of diabetes and pre-diabetes in Oke-Ogun region of Oyo state, Nigeria. J Med Res Health Educ 1:1

Stevens J, Katz EG, Huxley RR (2010) Associations between gender, age and waist circumference. Eur J Clin Nutr 64(1):6-15

Todkar SS (2016) Diabetes mellitus the 'Silent Killer' of mankind: an overview on the eve of upcoming World Health Day! J Med Allied Sci 6(1):39-44

Vaughan JP, Morrow RH (1989) Manual of epidemiology for District Health Management. WHO, Geneva, pp 126-128

Wang J, Stancakova A, Kuusisto J, Laakso M (2010) Identification of undiagnosed type 2 diabetic individuals by the Finnish diabetes risk score and biochemical and genetic markers: a population-based study of 7232 Finnish men.J Clin Endocrinol Metab 95.3858-3862

World Health Organization (2016) Global report on diabetes. Part 1: global burden of diabetes. World Health Organization, Geneva

Yu JS (2012) Genetics in diabetes mellitus-contribution to the classification and management. Ann Pediatr Endocrinol Metab 17:211-218

\section{Publisher's Note}

Springer Nature remains neutral with regard to jurisdictional claims in published maps and institutional affiliations. 